\title{
Illuminating Patterns of Perception: An Overview of Q Methodology
}

Maureen Brown

October 2004

Software Engineering Measurement and Analysis Initiative

Unlimited distribution subject to the copyright.

Technical Note

CMU/SEI-2004-TN-026 
This work is sponsored by the U.S. Department of Defense.

The Software Engineering Institute is a federally funded research and development center sponsored by the U.S. Department of Defense.

Copyright 2004 Carnegie Mellon University.

NO WARRANTY

THIS CARNEGIE MELLON UNIVERSITY AND SOFTWARE ENGINEERING INSTITUTE MATERIAL IS FURNISHED ON AN "AS-IS" BASIS. CARNEGIE MELLON UNIVERSITY MAKES NO WARRANTIES OF ANY KIND, EITHER EXPRESSED OR IMPLIED, AS TO ANY MATTER INCLUDING, BUT NOT LIMITED TO, WARRANTY OF FITNESS FOR PURPOSE OR MERCHANTABILITY, EXCLUSIVITY, OR RESULTS OBTAINED FROM USE OF THE MATERIAL. CARNEGIE MELLON UNIVERSITY DOES NOT MAKE ANY WARRANTY OF ANY KIND WITH RESPECT TO FREEDOM FROM PATENT, TRADEMARK, OR COPYRIGHT INFRINGEMENT.

Use of any trademarks in this report is not intended in any way to infringe on the rights of the trademark holder.

Internal use. Permission to reproduce this document and to prepare derivative works from this document for internal use is granted, provided the copyright and "No Warranty" statements are included with all reproductions and derivative works.

External use. Requests for permission to reproduce this document or prepare derivative works of this document for external and commercial use should be addressed to the SEI Licensing Agent.

This work was created in the performance of Federal Government Contract Number F19628-00-C-0003 with Carnegie Mellon University for the operation of the Software Engineering Institute, a federally funded research and development center. The Government of the United States has a royalty-free government-purpose license to use, duplicate, or disclose the work, in whole or in part and in any manner, and to have or permit others to do so, for government purposes pursuant to the copyright license under the clause at 252.227-7013.

For information about purchasing paper copies of SEI reports, please visit the publications portion of our Web site (http://www.sei.cmu.edu/publications/pubweb.html). 


\section{Contents}

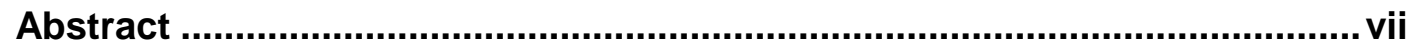

$1 \quad$ Introduction

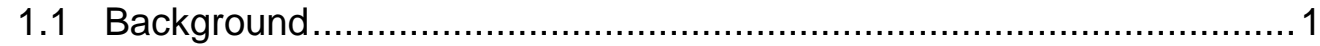

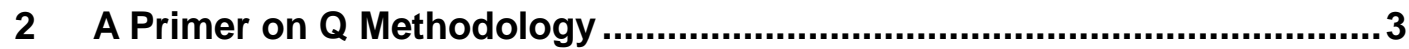

2.1 Stage 1: Establishing the Q-Sample ..................................................

2.2 Stage 2: Administering the Q-Sort ............................................... 4

2.3 Stage 3: Factor Analyzing the Q-Sort .................................................

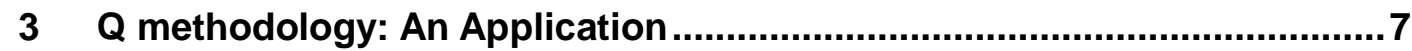

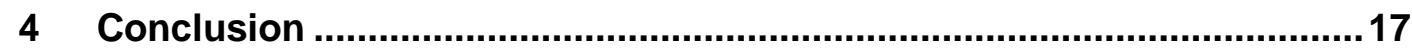

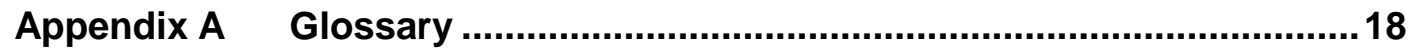

Appendix B Relevant Web Sites ...........................................................19

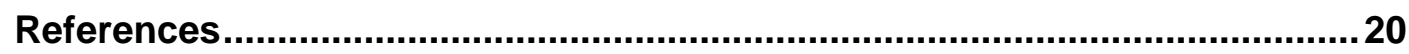


CMU/SEI-2004-TN-026 


\section{List of Figures}

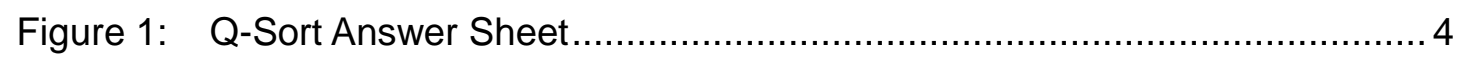


CMU/SEI-2004-TN-026 


\section{List of Tables}

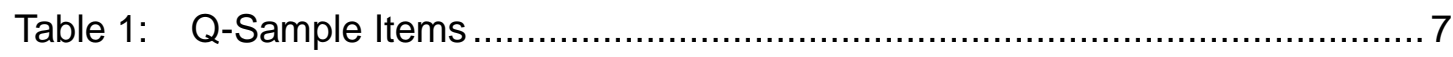

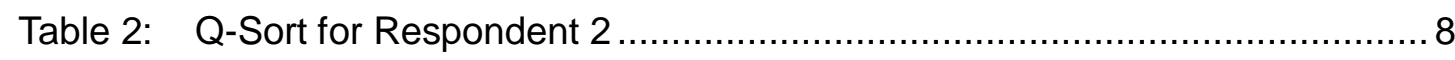

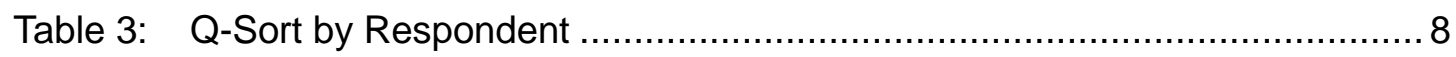

Table 4: Correlation Matrix between Sorts ............................................... 10

Table 5: $\quad$ Unrotated Factor Loadings....................................................... 10

Table 6: Factor Matrix with an X Indicating a Defining Sort ............................. 11

Table 7: Factor Q-Sort Values for Each Statement....................................... 12

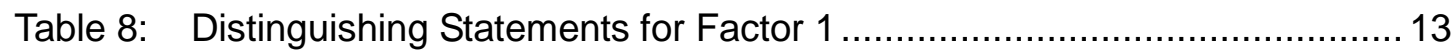

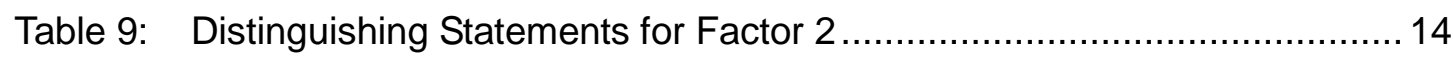

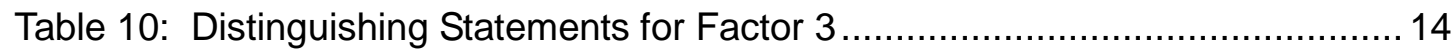

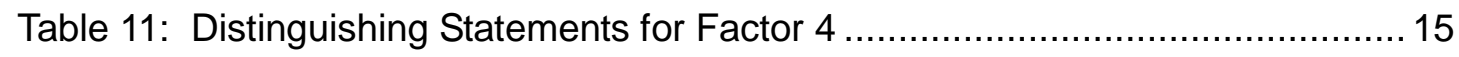

Table 12: Items That Do Not Distinguish between Any Pair of Factors................... 15 


\section{Abstract}

Q methodology is a research method with a proven history for illuminating agreement and differences among individual and group perceptions. This technical note describes ways for applying Q methodology to assist software engineering processes. As a project management tool, it can help to articulate system requirements and project risk. It can also be used to identify many of the hidden risks and costs associated with system efforts. Q methodology complements a project manager's suite of methodologies and tools by providing a means for uncovering stakeholder perceptions of incorrectly specified requirements, looming risks, and hidden costs. In doing so, it provides stakeholders and project managers with additional insights for troubleshooting project threats. 


\section{Introduction}

\subsection{Background}

Q methodology is a research technique that allows a researcher to 1) identify, understand, and categorize individual perceptions and opinions, and 2) cluster groups based on their perceptions [McKeown \& Thomas 88].

Invented in 1935 by British physicist-psychologist William Stephenson, Q methodology is most often associated with quantitative analysis because of its reliance on factor analysis [Stephenson 53]. Statistical procedures aside, Stephenson was interested in providing a way to reveal the subjectivity involved in any situation; e.g., in perceptions of risk, appraisal of costs, perspectives on user requirements, and opinions on training. Q methodology allows researchers to examine the subjective perceptions of individuals on any number of topics. It also helps to identify commonalities and differences in subjective perceptions across a sample group.

The real utility of Q methodology lies in uncovering these opinion/perception clusters. Once identified, they can be targeted for follow-up activities such as further research or programmatic activities. It is the combination of qualitative and quantitative research techniques that allows researchers to identify individuals who share common opinions. Q methodology is often used for the following:

- identifying important internal and external constituencies

- defining participant viewpoints and perceptions

- providing sharper insight into preferred management directions

- identifying criteria that are important to clusters of individuals

- examining areas of friction, consensus, and conflict

- isolating gaps in shared understanding [Steelman \& Maguire 04]

The qualitative aspect of Q methodology is grounded in its ability to emphasize the how and why people think the way they do. The primary goal is to uncover different patterns of thought—not to count how many people think the way they do [Valenta \& Wigger 97]. The quantitative aspect involves using factor analytic techniques (specifically, principle components analysis [PCA]) as a means for grouping like-minded individuals. 
In short, Q methodology provides analysts with "a systematic and rigorously quantitative means for examining human subjectivity" [McKeown \& Thomas 88].

In terms of systems development, Q methodology may be useful for the following:

- understanding and mitigating pockets of resistance in system adoption

- targeting and tailoring system features, training needs, or security requirements

- isolating data standards requirements for system integration

- tailoring system performance measures and metrics

- understanding system risk elements

- tailoring checklists and criteria for understanding cost, schedule, and sizing estimates

Section 2 provides a brief introduction to Q methodology and Section 3 illustrates how it can be used in a software context. 


\section{A Primer on Q Methodology}

Q methodology, like many research methods, can be used to observe perceptions from the context of an individual or from the context of a group of individuals. In Q methodology, intrasubjective studies gather data from an individual on multiple issues of interest. The individual's opinions are then clustered based on similarity of opinion. The purpose is to determine whether the various opinions of the individual give rise to a greater thematic understanding of the issues at hand. Typically, an individual may be asked to reveal his/her perceptions on a variety of different constructs. When examined in total, the findings may reveal similarity patterns. For example, a programmer may be studied to determine his/her preferences for different software programming methodologies under various conditions. In this case, the study is intrasubjective because the researcher is studying a single individual to determine if preferences cluster around one or more common themes.

Conversely, intersubjective studies focus on how perceptions of groups of people cluster on one issue or more. The issue may be single or multidimensional. The point being, if one was only concerned about how various traits clustered together, they would be employing traditional factor analysis methods. Alternatively, Q methodology is concerned with clustering like-minded perceptions. It is a means for identifying the presence of patterns of opinions. Whether it is single dimensional or multidimensional, the study is always framed around finding patterns of subjective perceptions.

As illustrated below, the methodology features three distinct stages of activities: establishing the Q-Sample, administering the Q-Sort, and factor analyzing the Q-Sorts.

\subsection{Stage 1: Establishing the Q-Sample}

Establishing the Q-Sample involves identifying the survey items-not the participants or statements that will be used to identify individual patterns of perceptions. Because the survey items are perceptual in nature, they tend to reflect subjective statements pertaining to the particular research area of interest. (Later, during the Q-Sort procedure, the participants will be asked to rank order these survey items according to their individual level of agreement.) This collection of items, termed the concourse, is not restricted to textual material but has been known to include paintings, art work, photographs, or even musical selections [Brown 93]. While the actual items may take different forms, the scale on which participants sort the items remains fixed. For example, a participant may be asked to rate, on a scale of -5 to +5 , the degree to which they agree with the statement: "the software process would benefit more from additional investments in quality assurance (QA) than additional investments in system design." 
The survey items (or statements) that compose the concourse can be derived in numerous ways. Typically, the items are collected through personal interviews and focus groups. Focus group discussions often reveal the multiplicity of subjective perceptions and allow the researcher to design specific survey items that drill down into particular attitudes. Other sources for survey items may include journal publications or newspaper articles. The primary point is that the collection of items in the concourse should reflect the range of perceptions on a particular topic of interest. In many cases, researchers will pilot test the concourse to verify its validity. Because participants are asked to sort the statements in a particular manner (see Section 2.2), most Q-Samples consist of 33 items. However, they are not restricted to 33 and can employ any number of items. After the Q-Sample is constructed, each item in the sample is numbered for data recording purposes.

It should be noted that the goal of the Q-Sample is to provide, in miniature, a comprehensive portrayal of the larger process being modeled [Brown 93]. To ensure content validity, sample statements are usually reviewed by domain experts and tested in one or more pilot studies. In terms of comprehensiveness and representativeness of any given Q-Sample, the design of the instrument is performed just as carefully as participant selection is conducted for survey studies. Hence, some researchers prefer to develop a larger set of items and then select a random sample of items to administer.

Because Q methodology does not seek to make claims to larger representative groups, it is less concerned with participant sampling techniques. There is often the assumption that $\mathrm{Q}$ methodology participants represent the total population. In Stage 1, given the focus is on capturing a wide array of perceptions, the rigor that is often associated with identifying the target sample is redirected toward identifying the survey items. The target goal of the QSample is a comprehensive, balanced, and representative set of survey items. Once the QSample has been designed it is released for "sorting."

\subsection{Stage 2: Administering the Q-Sort}

Stage 2 involves administering the Q-Sort or collecting participant perceptions. When administering the Q-Sort, participants are often given a sheet with specific sorting instructions called a condition of instruction and an answer sheet to record the rank ordering (see Figure 1).

\begin{tabular}{|c||c||c||c||c|c|c|c|c|}
\hline \multicolumn{2}{|l|}{ Most Disagree } \\
\hline \hline-4 & -3 & -2 & -1 & 0 & +1 & +2 & +3 & +4 \\
\hline \hline & & & & & & & & \\
\hline & & & & & & & & \\
\hline & & & & & & & & \\
\hline & & & & & & & & \\
\hline & & & & & & & & \\
\hline & & & & & & & & \\
\hline
\end{tabular}

Figure 1: Q-Sort Answer Sheet 
In this stage, participants are asked to sort the opinion statements into a predefined set of categories, ranging from "Most Agree" to "Most Disagree." As noted in Figure 1, the answer form that participants use to sort the survey items forces the Q-Sort into the shape of a normal distribution. There are fewer statements that can be placed at either end, allowing more to be place in the middle (or neutral) zone of the scale.

The Q-Sample is administered to each participant and his or her individual, rank-ordered statements are then recorded. The resulting data matrix will reflect the participant's sorting arrangements in the column with the survey item statement along the row. The ranking level of each item is then entered into the data matrix to allow factor analysis. Because each item is measured according to the individual's perception, and on the same scale, the individual's specific array can be correlated with the arrays of the other participants. The data can then be analyzed with a variety of statistical tools (see Section 2.3). The outcomes of this stage should be a data matrix of the participants' rank ordering of each of the survey items in the Q-Sample. Given that respondents, or participants, array their perceptions in a forced matrix reflecting a normal distribution curve, participants can be correlated and grouped according to their level of agreement or similarity — the goal of the next stage.

\subsection{Stage 3: Factor Analyzing the Q-Sort}

Data analysis in Q methodology typically involves the sequential application of three sets of statistical procedures: correlation, factor analysis, and the computation of factor scores. The discussion below speaks briefly to each of these issues. Readers are encouraged to examine the citations provided below to develop a deeper understanding of these specific statistical tools. It should be noted that while the steps are discussed below, most statistical software generates these procedures automatically. Hence the discussion is intended to describe what is occurring, not to provide a concrete list of instructions.

The first step in analyzing the data is to generate a correlation matrix of the participants. As Brown has shown [Brown 93], it makes no difference whether the coefficients in the correlation matrix are Pearson's $r$, Spearman's rho, or other commonly employed nonparametric measures of association. As a practical matter, the factoring process commences once a matrix of Q-Sort correlations is provided.

According to a variety of research findings, it makes little difference whether the specific factoring routine is principal components, centroid, or any other available method. Regardless of the precise procedures employed, the resultant factor structures do not appear to differ from one another in any appreciable respects [McKeown \& Thomas 88]. By convention, PCA with a Varimax rotation is the most common routine employed. (For detailed elaboration, see Adcock [Adcock 54] or Brown [Brown 80]). Hence the case examined below focuses on analyzing Q-Sorts using PCA with the Varimax method of orthogonal rotation. 
The result of the factor analysis is factor loadings. Factor loadings are in effect correlation coefficients: they indicate the extent to which each Q-Sort (i.e., participant) is similar or dissimilar to the composite factor array. In most research applications, factor interpretation proceeds on the basis of factor loadings. In Q methodology, on the other hand, interpretations are based on factor scores which reflect the extent of agreement among perceptions related to the individual Q-Sort statements. In Q methodology the presence of several orthogonal (independent) factors is evidence of different points of view in the participant-sample. An individual's positive loading on a factor indicates his or her shared subjectivity with others on that factor; negative loadings, on the other hand, are signs of rejection of the factor's perspective [McKeown \& Thomas 88]. The case presented in the following section illustrates the analysis and interpretation of a group of city and county chief executive officers (CEOs) to understand the types of information technology (IT) assistance they perceived would be most helpful to local governments. 


\section{Q methodology: An Application}

The following illustration is based on a government agency's attempt to isolate potential investment strategies for supporting the software efforts of 13 sister agencies. The study sought to identify CEO perceptions of areas of consensus and conflict over how to best support their software engineering efforts in an era of limited funds. The results of the study were used to help define the resource investment strategies for supporting the 13 organizations. The study began with a focus group discussion to identify the relevant concourse of Q-Sample items. Based on the discussion and dialogue, 33 items were derived, and thus composed the Q-Sample (see Table 1).

\section{Table 1: Q-Sample Items}

\begin{tabular}{|c|c|}
\hline Item \# & In my opinion resource investments should be made in assisting with: \\
\hline 1 & data policies \\
\hline 2 & emerging privacy legislation \\
\hline 3 & emerging security legislation \\
\hline 4 & ethical use of software, technology, and data \\
\hline 5 & changes in business related standard operating procedures \\
\hline 6 & changes in IT related standard operating procedures \\
\hline 7 & ADA requirements \\
\hline 8 & data sharing \\
\hline 9 & prototyping new software solutions \\
\hline 10 & technical requirements definition \\
\hline 11 & code inspections \\
\hline 12 & test program reviews \\
\hline 13 & screen design, format, and layout \\
\hline 14 & disaster recovery \\
\hline 15 & engineering documents \\
\hline 16 & technical documentation \\
\hline 17 & training investments \\
\hline 18 & ROI strategies \\
\hline 19 & quality assurance \\
\hline 20 & risk management \\
\hline 21 & estimating cost and schedule \\
\hline 22 & communications and team building \\
\hline 23 & visioning/strategic planning and goal alignment \\
\hline 24 & contracting and outsourcing \\
\hline 25 & auditing and post-mortems \\
\hline
\end{tabular}




\begin{tabular}{|l|l|}
\hline 26 & productivity changes \\
\hline 27 & cost savings \\
\hline 28 & process improvement \\
\hline 29 & added value \\
\hline 30 & leveraging organizational information and knowledge \\
\hline 31 & developing feasible and reliable metrics \\
\hline 32 & citizen engagement \\
\hline 33 & transparency and accountability \\
\hline
\end{tabular}

The Q-Sample was administered and the CEOs were asked to sort the items in terms of their level of agreement with investing resources in the area on a -4 to +4 scale. All participants sorted their responses according to a "forced" normal distribution curve. Thus only a limited number of $+4 \mathrm{~s},+3 \mathrm{~s}$, etc. were allowed. Table 2 illustrates the Q-Sort for Respondent 2 (R2). As demonstrated in the table, $\mathrm{R} 2$ ranked item 1 (data policies) and item 28 (process improvement) $\mathrm{a}+4$, indicating a strong preference for the greatest investment. Conversely, items 5 and 6 (changes in business related standard operating procedures and changes in IT related standard operating procedures) were rated a -4 , indicating perceptions of areas for least investment.

Table 2: Q-Sort for Respondent 2

\begin{tabular}{|c|c|c|c|c|c|c|c|c|}
\hline-4 & -3 & -2 & -1 & 0 & +1 & +2 & +3 & +4 \\
\hline 5 & 15 & 9 & 19 & 3 & 7 & 2 & 17 & 1 \\
\hline 6 & 25 & 10 & 22 & 4 & 21 & 14 & 23 & 28 \\
\hline & 31 & 11 & 26 & 12 & 24 & 33 & 18 & \\
\hline & & 16 & 29 & 13 & 27 & 8 & & \\
\hline & & & 32 & 20 & 30 & & & \\
\hline & & & & & & & & \\
\hline
\end{tabular}

The data for all 13 CEOs were collected and entered in a data matrix (see Table 3). In keeping with the $\mathrm{Q}$ methodology process, individual respondents were listed along the column and Q-Sample items along the row.

Table 3: Q-Sort by Respondent

\begin{tabular}{|l|l|l|l|l|l|l|l|l|l|l|l|l|l|}
\hline $\begin{array}{l}\text { Respondent } \\
\text { Item }\end{array}$ & $\mathbf{1}$ & $\mathbf{2}$ & $\mathbf{3}$ & $\mathbf{4}$ & $\mathbf{5}$ & $\mathbf{6}$ & $\mathbf{7}$ & $\mathbf{8}$ & $\mathbf{9}$ & $\mathbf{1 0}$ & $\mathbf{1 1}$ & $\mathbf{1 2}$ & $\mathbf{1 3}$ \\
\hline 1 & -2 & 4 & 3 & -1 & 4 & 3 & 2 & 4 & 4 & 4 & 3 & 0 & 4 \\
\hline 2 & -1 & 2 & -3 & 0 & -2 & -3 & -3 & -1 & -2 & -1 & 2 & -1 & -4 \\
\hline 3 & -2 & 0 & 0 & -3 & 2 & -3 & -3 & -1 & -2 & -1 & 1 & 4 & -4 \\
\hline 4 & -1 & 0 & 3 & 2 & 1 & -4 & 0 & -2 & 2 & -4 & 1 & -2 & -3 \\
\hline 5 & -1 & -4 & 0 & 3 & 4 & 2 & 4 & 2 & 3 & 3 & -1 & 0 & -3 \\
\hline 6 & -1 & -4 & 0 & 0 & 3 & 2 & 3 & 3 & 0 & 4 & -2 & 0 & -3 \\
\hline 7 & 0 & 1 & -4 & -1 & 2 & -1 & -4 & -3 & -1 & -3 & -3 & -1 & -2 \\
\hline
\end{tabular}




\begin{tabular}{|c|c|c|c|c|c|c|c|c|c|c|c|c|c|}
\hline 8 & -1 & 2 & 4 & 4 & 3 & 2 & 0 & 0 & 2 & -2 & -1 & 0 & 1 \\
\hline 9 & 2 & -2 & 2 & 2 & 2 & 4 & 3 & 0 & 1 & 1 & -3 & 2 & 0 \\
\hline 10 & -2 & -2 & -1 & 1 & 2 & 1 & 1 & 1 & -4 & 1 & -1 & 1 & -1 \\
\hline 11 & -2 & -2 & -3 & -3 & 0 & -3 & -1 & 1 & -3 & 0 & -3 & -1 & 0 \\
\hline 12 & -3 & 0 & 1 & -2 & 1 & 2 & -1 & 0 & 0 & -1 & -2 & -2 & -2 \\
\hline 13 & -3 & 0 & -1 & -1 & 1 & -2 & -4 & -3 & -4 & -2 & -4 & 1 & -2 \\
\hline 14 & -3 & 2 & -1 & 1 & 1 & 3 & -3 & -3 & 0 & 1 & 0 & -3 & 0 \\
\hline 15 & -4 & -3 & 4 & -1 & 0 & 4 & -2 & -2 & -1 & 0 & -2 & -4 & 1 \\
\hline 16 & -4 & -2 & -1 & 0 & 1 & 3 & -2 & -2 & -1 & 0 & 0 & -3 & 0 \\
\hline 17 & 0 & 3 & -2 & -2 & -3 & -2 & 2 & 1 & 2 & -1 & 1 & -3 & 3 \\
\hline 18 & 1 & 3 & 1 & 1 & 3 & 1 & 1 & 0 & 1 & -1 & 3 & -4 & 2 \\
\hline 19 & 1 & -1 & 0 & 2 & 0 & 0 & 1 & 1 & -1 & 1 & 2 & 2 & 3 \\
\hline 20 & 1 & 0 & 0 & -2 & 0 & -2 & 0 & 0 & 0 & 1 & 0 & 0 & 2 \\
\hline 21 & 0 & 1 & 1 & 0 & 0 & 0 & 0 & 2 & 0 & 0 & 2 & 1 & 2 \\
\hline 22 & 1 & -1 & 2 & 3 & 0 & -2 & 0 & 2 & 3 & 0 & 1 & 3 & 2 \\
\hline 23 & 2 & 3 & 2 & 1 & -1 & 1 & 3 & 4 & 4 & 3 & 4 & 2 & 3 \\
\hline 24 & 4 & 1 & -2 & 0 & -4 & 1 & 2 & 3 & 0 & -3 & 3 & 1 & 0 \\
\hline 25 & 0 & -3 & 1 & -3 & -4 & 0 & 0 & -4 & -1 & 0 & 0 & 0 & -2 \\
\hline 26 & 3 & -1 & 0 & 1 & -1 & 0 & -1 & 1 & 1 & -2 & 4 & 3 & 1 \\
\hline 27 & 3 & 1 & 2 & -2 & -3 & 1 & 2 & 0 & -3 & -2 & 2 & 2 & 4 \\
\hline 28 & 4 & 4 & -1 & 4 & -1 & 0 & 4 & 3 & 1 & 2 & 1 & 1 & -1 \\
\hline 29 & 0 & -1 & 1 & -4 & -1 & -1 & -1 & -1 & -2 & -3 & 0 & 4 & 1 \\
\hline 30 & 2 & 1 & -2 & 3 & -2 & 0 & -1 & -1 & 2 & 2 & 0 & -1 & -1 \\
\hline 31 & 1 & -3 & -2 & -4 & -3 & -4 & -2 & -2 & -2 & 2 & -1 & -2 & 0 \\
\hline 32 & 0 & -1 & 3 & -1 & -2 & -1 & 1 & -4 & 3 & -4 & -1 & 3 & 1 \\
\hline 33 & 2 & 2 & -3 & 2 & -2 & -1 & -2 & -1 & 1 & 3 & -2 & -1 & -1 \\
\hline
\end{tabular}

The next step is to obtain the correlation matrix of the Q-Sorts (Table 4). As noted in the table, R1 correlates with R5 in the amount of .51, and a quick perusal down the column shows a weak correlation with R3 and R4 (.34 and .32, respectively). R3, on the other hand, shows a fairly moderate correlation with R4, R5, and R7 (.69, .49, and .46).

It should be noted that Q-Sort correlations are rarely of any interest in and of themselves. This is because we are not as interested in how closely two people correlate as we are in tapping dominant perceptions of the group in its entirety. Hence, the correlation matrix represents merely a phase through which the data pass on the way to factor analysis [Sell \& Brown 84]. 
Table 4: $\quad$ Correlation Matrix between Sorts

\begin{tabular}{|rrrrrrrrrrrrrr|}
\hline SORTS & $\mathbf{1}$ & $\mathbf{2}$ & $\mathbf{3}$ & $\mathbf{4}$ & $\mathbf{5}$ & $\mathbf{6}$ & $\mathbf{7}$ & $\mathbf{8}$ & $\mathbf{9}$ & $\mathbf{1 0}$ & $\mathbf{1 1}$ & $\mathbf{1 2}$ & $\mathbf{1 3}$ \\
\hline$r 1$ & 100 & 29 & 34 & 32 & 51 & 23 & 27 & 23 & $\mathbf{1 4}$ & $\mathbf{1}$ & $\mathbf{1 3}$ & 31 & -3 \\
\hline$r 2$ & 29 & 100 & 7 & 20 & 15 & 23 & -49 & -7 & -23 & -9 & 26 & 38 & -15 \\
\hline$r 3$ & 34 & 7 & 100 & 69 & 49 & 34 & 46 & 4 & 32 & 22 & 35 & 35 & 33 \\
\hline$r 4$ & 32 & 20 & 69 & 100 & 37 & 47 & 35 & 25 & 46 & 24 & 8 & 22 & 34 \\
\hline$r 5$ & 51 & 15 & 49 & 37 & 100 & 24 & 27 & 33 & 35 & 0 & 40 & 23 & 28 \\
\hline$r 6$ & 23 & 23 & 34 & 47 & 24 & 100 & 2 & -4 & -1 & -13 & -11 & 32 & 6 \\
\hline$r 7$ & 27 & -49 & 46 & 35 & 27 & 2 & 100 & 28 & 44 & 40 & -12 & -15 & 28 \\
\hline$r 8$ & 23 & -7 & 4 & 25 & 33 & -4 & 28 & 100 & 47 & -9 & -6 & -4 & 33 \\
\hline$r 9$ & 14 & -23 & 32 & 46 & 35 & -1 & 44 & 47 & 100 & 20 & 18 & -1 & 44 \\
\hline$r 10$ & 1 & -9 & 22 & 24 & 0 & -13 & 40 & -9 & 20 & 100 & 20 & -16 & 9 \\
\hline$r 11$ & 13 & 26 & 35 & 8 & 40 & -11 & -12 & -6 & 18 & 20 & 100 & 38 & 37 \\
\hline$r 12$ & 31 & 38 & 35 & 22 & 23 & 32 & -15 & -4 & -1 & -16 & 38 & 100 & 23 \\
\hline$r 13$ & -3 & -15 & 33 & 34 & 28 & 6 & 28 & 33 & 44 & 9 & 37 & 23 & 100 \\
\hline Note: Decimals to two places omitted & & & & & & & & & & \\
\hline
\end{tabular}

Once the correlation matrix is obtained, the factor analysis process begins (an unrotated factor matrix is computed and Eigenvalues are identified). The Eigenvalues reflect the amount of variation accounted for by the corresponding factor. In essence, the relative magnitude of the Eigenvalues can be used to order the importance of the factors. By convention, factors with Eigenvalues greater than 1.00 are considered significant; those with Eigenvalues of lesser value are considered too weak to warrant serious attention.

For this size sample, factor loadings in excess of .45 are considered significant ( $\mathrm{p}<.01)$. Referring to Table 5 factor 1 , the loadings of R1, R3, R4, R5, R7, and R9 (.54, .79, .77, .71, .53 , and .62 respectively) mean that the Q-Sorts in their totality for each person demonstrates a common perspective, or are highly correlated. The Eigenvalue of 3.73 is considered significant and thus, factor 1 appears to represent a common viewpoint held by a number of the respondents. The Eigenvalues for factors 2, 3, and 4 are also significant $(2.3,1.4$, and 1.3 respectively). While factor 5 appears to demonstrate borderline significance (Eigenvalue $=$ 1.06), perusing the columns reveals that since only two respondents ( $R 1$ and $R 13$ ) were loaded significantly, the factor did not constitute a large enough group to merit further examination. Hence the first four factors were identified as candidates for further analysis.

Table 5: Unrotated Factor Loadings

\begin{tabular}{|l|ccccccccc|}
\hline SORTS & Factors & 1 & 2 & 3 & 4 & 5 & 6 & 7 & 8 \\
\hline r1 & & 0.5426 & 0.2893 & -0.3061 & -0.1161 & 0.5690 & -0.1729 & 0.2301 & 0.0080 \\
\hline r2 & 0.1000 & 0.7930 & 0.0314 & -0.0216 & 0.2049 & 0.4741 & 0.0322 & 0.0536 \\
\hline r3 & 0.7975 & 0.0910 & -0.0245 & 0.3505 & -0.0821 & -0.1689 & -0.0914 & -0.1712 \\
\hline r4 & 0.7767 & 0.0401 & -0.2650 & 0.2174 & -0.2016 & 0.3568 & -0.0172 & -0.1199 \\
\hline
\end{tabular}




\begin{tabular}{|c|c|c|c|c|c|c|c|c|}
\hline r5 & 0.7152 & 0.1459 & 0.0232 & -0.2443 & 0.2944 & -0.2050 & -0.4195 & 0.1424 \\
\hline r6 & 0.3731 & 0.4166 & -0.5484 & 0.1631 & -0.4020 & -0.0046 & -0.1690 & 0.2243 \\
\hline r7 & 0.5382 & -0.6394 & -0.2230 & 0.2097 & 0.1339 & -0.2727 & 0.1583 & 0.0677 \\
\hline r8 & 0.4119 & -0.3223 & -0.1397 & -0.6877 & 0.0908 & 0.2724 & 0.1562 & 0.1525 \\
\hline r9 & 0.6241 & -0.4545 & 0.1129 & -0.2267 & -0.0730 & 0.2306 & -0.0739 & -0.3979 \\
\hline $\mathrm{r} 10$ & 0.2503 & -0.3609 & 0.2595 & 0.6549 & 0.2832 & 0.3112 & 0.1487 & 0.2223 \\
\hline $\mathrm{r} 11$ & 0.4066 & 0.3035 & 0.7821 & 0.0344 & 0.1238 & -0.0660 & -0.1543 & -0.0002 \\
\hline $\mathrm{r} 12$ & 0.3906 & 0.6377 & 0.1741 & -0.0493 & -0.2238 & -0.2336 & 0.4577 & -0.1239 \\
\hline r13 & 0.5619 & -0.2160 & 0.4139 & -0.2067 & -0.4724 & -0.0300 & 0.1149 & 0.3137 \\
\hline Eigenvalues & 3.7395 & 2.3121 & 1.4293 & 1.3139 & 1.0617 & 0.8109 & 0.5907 & 0.4665 \\
\hline$\%$ expl.Var. & 29 & 18 & 11 & 10 & 8 & 6 & 5 & 4 \\
\hline
\end{tabular}

Table 6: Factor Matrix with an X Indicating a Defining Sort

\begin{tabular}{|c|c|c|c|c|}
\hline & Loadings & & & \\
\hline Q-SORT & 1 & 2 & 3 & 4 \\
\hline $\mathrm{r} 1$ & -0.1029 & $0.6442 \mathrm{X}$ & 0.1156 & 0.2153 \\
\hline $\mathrm{r} 2$ & -0.3271 & 0.3842 & 0.5380 & -0.3102 \\
\hline r3 & 0.5105 & 0.6165 & 0.2706 & 0.2320 \\
\hline $\mathrm{r} 4$ & 0.3629 & $0.7102 \mathrm{X}$ & 0.0588 & 0.2879 \\
\hline r5 & 0.0005 & 0.4702 & 0.3222 & 0.5178 \\
\hline r6 & -0.0582 & $0.7818 \mathrm{X}$ & -0.0382 & -0.1549 \\
\hline $\mathrm{r} 7$ & 0.5853 & 0.2367 & -0.3969 & 0.4858 \\
\hline r8 & -0.2864 & 0.1088 & -0.1682 & $0.8024 \mathrm{X}$ \\
\hline r9 & 0.2711 & 0.0995 & 0.0066 & $0.7595 \mathrm{X}$ \\
\hline $\mathrm{r} 10$ & $0.8270 \mathrm{X}$ & -0.0594 & 0.0357 & -0.0223 \\
\hline $\mathrm{r} 11$ & 0.2244 & -0.0869 & $0.8794 \mathrm{X}$ & 0.1973 \\
\hline $\mathrm{r} 12$ & -0.1428 & 0.4107 & $0.6344 X$ & -0.0173 \\
\hline r13 & 0.2315 & -0.0202 & 0.3412 & $0.6372 X$ \\
\hline$\%$ expl.Var. & 14 & 20 & 15 & 19 \\
\hline
\end{tabular}


In Q methodology, interpretations are based on factor arrays and factor scores rather than the loadings (as per typical factor analytic techniques). After controlling for the weighting of each of the factor loadings, a composite Q-Sort (termed the array) can be uncovered for each of the factors. As shown in Table 7, these factor arrays reflect an overall Q-Sample for the respondents who loaded on the factor in total. Based on these factor arrays, we can identify the distinguishing statements (items) that are associated with each factor. It is in this way that we can begin to see the pattern of thoughts that arises specific to each of the four groups.

\section{Table 7: Factor Q-Sort Values for Each Statement}

\begin{tabular}{|c|c|c|c|c|c|c|}
\hline \multicolumn{7}{|c|}{ Factor Arrays } \\
\hline No. & Statement & No. & $\mathbf{1}$ & 2 & 3 & 4 \\
\hline 1 & data policies & 1 & -1 & 4 & 3 & 4 \\
\hline 2 & emerging privacy legislation & 2 & -2 & -1 & -4 & 1 \\
\hline 3 & emerging security legislation & 3 & 4 & -2 & -1 & -1 \\
\hline 4 & ethical use of software, technology, and data & 4 & -2 & -2 & 2 & 0 \\
\hline 5 & changes in business-related standard operation procedures (SOP) & 5 & -1 & 3 & 0 & -4 \\
\hline 6 & changes in IT related SOP & 6 & -1 & 3 & 0 & -4 \\
\hline 7 & ADA requirements & 7 & -2 & -3 & -4 & -1 \\
\hline 8 & data sharing & 8 & -1 & 1 & 4 & 1 \\
\hline 9 & prototyping new software solutions & 9 & 2 & 1 & 3 & -3 \\
\hline 10 & technical requirements definition & 10 & 1 & 1 & -1 & -2 \\
\hline 11 & code inspections & 11 & -2 & 0 & -4 & -3 \\
\hline 12 & test program reviews & 12 & -2 & -2 & 2 & -1 \\
\hline 13 & screen design, format, and layout & 13 & 1 & -3 & -2 & -3 \\
\hline 14 & disaster recovery & 14 & -3 & 0 & -1 & 1 \\
\hline 15 & engineering documents & 15 & -4 & -1 & 4 & -2 \\
\hline 16 & technical documentation & 16 & -3 & -1 & -1 & -1 \\
\hline 17 & training investments & 17 & -3 & -1 & -2 & 3 \\
\hline 18 & ROI strategies & 18 & -4 & 0 & 1 & 3 \\
\hline 19 & quality assurance & 19 & 2 & 2 & 0 & 1 \\
\hline 20 & risk management & 20 & -1 & 1 & -1 & 1 \\
\hline 21 & estimating cost and schedule & 21 & 1 & 1 & 1 & 2 \\
\hline 22 & communications and team building & 22 & 3 & 2 & 1 & 0 \\
\hline
\end{tabular}




\begin{tabular}{|c|c|c|c|c|c|c|}
\hline 23 & visioning/strategic planning \& goal alignment & 23 & 2 & 4 & 2 & 4 \\
\hline 24 & contracting and outsourcing & 24 & 1 & 0 & -2 & 2 \\
\hline 25 & auditing and post-mortems & 25 & -1 & -3 & 1 & -2 \\
\hline 26 & productivity changes & 26 & 3 & 0 & 0 & 2 \\
\hline 27 & cost savings & 27 & 2 & -2 & 2 & 3 \\
\hline 28 & process improvement & 28 & 1 & 3 & -1 & 2 \\
\hline 29 & added value & 29 & 4 & -4 & 1 & 0 \\
\hline 30 & leveraging organizational info and knowledge & 30 & -2 & 2 & -2 & 0 \\
\hline 31 & developing feasible and reliable metrics & 31 & -2 & -1 & -3 & -2 \\
\hline 32 & citizen engagement & 32 & 3 & -4 & 3 & -1 \\
\hline 33 & transparency and accountability & 33 & -2 & 2 & -3 & 0 \\
\hline
\end{tabular}

Referring back to Table 6, Respondents 3, 7, and 10 comprise factor 1. As illustrated in Table 8 , factor 1 identifies that the grouping shared strong opinions on the need for investments in "understanding and defining security legislation" and "achieving added value" from their systems. Note that these two items received a +4 on the Q-Sort. The respondents did not see "data policies," "disaster recovery," or "returns-on-investment" as areas for investment.

Table 8: Distinguishing Statements for Factor $1^{1}$

\begin{tabular}{|c|c|c|c|c|c|c|c|c|c|}
\hline & & \multicolumn{8}{|c|}{ Factors } \\
\hline & & \multicolumn{2}{|l|}{1} & \multicolumn{2}{|l|}{2} & \multicolumn{2}{|l|}{3} & \multicolumn{2}{|c|}{4} \\
\hline No. Statement & No. & \multicolumn{2}{|c|}{ RNK SCORE } & \multicolumn{2}{|c|}{ RNK SCORE } & \multicolumn{2}{|c|}{ RNK SCORE } & \multicolumn{2}{|c|}{ RNK SCORE } \\
\hline 3 emerging security legislation & 3 & 4 & $1.78 *$ & -2 & -0.85 & -1 & -0.38 & -1 & -0.29 \\
\hline 29 added value & 29 & 4 & $1.78 *$ & -4 & -1.51 & 1 & 0.25 & 0 & -0.16 \\
\hline 13 screen design, format, layout & 13 & 1 & 0.43 & -3 & -1.20 & 2 & -0.69 & 3 & -1.10 \\
\hline 1 data policies & 1 & -1 & $-0.03 *$ & 4 & 1.68 & 3 & 1.52 & 4 & 2.06 \\
\hline 14 disaster recovery & 14 & -3 & -1.39 & 0 & -0.13 & -1 & -0.15 & 1 & 0.47 \\
\hline 18 ROI strategies & 18 & -4 & $-1.84 *$ & 0 & -0.09 & 1 & 0.47 & 3 & 1.58 \\
\hline
\end{tabular}

Turning our attention to Table 9, Respondents 1, 3, 4, and 6 illustrate the need for investments in "standard operating procedures for IT and business related practices" that

${ }^{1}$ Both the Factor Q-Sort Value and the Normalized Score are shown for Tables 8 through 11. 
impact system efforts. They also hang together in their impressions of the need for investment in determining ways to achieve "transparency and accountability gains" from systems. They are in agreement, albeit not concerned, with investing efforts in "cost savings," "added value," and "citizen engagement."

\section{Table 9: Distinguishing Statements for Factor 2}

\begin{tabular}{|c|c|c|c|c|c|c|c|c|c|}
\hline \multicolumn{10}{|c|}{ Factors } \\
\hline & & 1 & & 2 & & 3 & & 4 & \\
\hline No. Statement & No. & \multicolumn{2}{|c|}{ RNK SCORE } & \multicolumn{2}{|c|}{ RNK SCORE } & \multicolumn{2}{|c|}{ RNK SCORE } & \multicolumn{2}{|c|}{ RNK SCORE } \\
\hline 6 changes in IT related SOP & 6 & -1 & -0.03 & 3 & $1.64 *$ & 0 & 0.16 & -4 & -1.79 \\
\hline 5 changes in business related SOP & 5 & -1 & -0.03 & 3 & $1.61 *$ & 0 & 0.16 & -4 & -1.58 \\
\hline 33 transparency and accountability & 33 & -2 & -0.48 & 2 & 0.91 & -3 & -1.41 & 0 & -0.07 \\
\hline 27 cost savings & 27 & 2 & 0.88 & -2 & $-0.78 *$ & 2 & 0.89 & 3 & 1.11 \\
\hline 29 added value & 29 & 4 & 1.78 & -4 & $-1.51 *$ & 1 & 0.25 & 0 & -0.16 \\
\hline 32 citizen engagement & 32 & 3 & 1.33 & -4 & $-1.91 *$ & 3 & 1.09 & -1 & -0.37 \\
\hline
\end{tabular}

Table 10: Distinguishing Statements for Factor 3

\begin{tabular}{|c|c|c|c|c|c|c|c|c|c|}
\hline \multicolumn{10}{|c|}{ Factors } \\
\hline & \multicolumn{3}{|c|}{1} & \multicolumn{2}{|l|}{2} & \multicolumn{2}{|l|}{3} & \multicolumn{2}{|l|}{4} \\
\hline No. Statement & No. & RNK & SCORE & $\mathrm{RNK}$ & SCORE & $\mathrm{RN}$ & SCORE & $\mathrm{RNI}$ & SCORE \\
\hline 15 engineering documents & 15 & $-4-$ & 1.84 & -1 & -0.49 & 4 & $2.05 *$ & -2 & -1.07 \\
\hline 8 data sharing & 8 & -1 & -0.03 & 1 & 0.07 & 4 & $1.83 *$ & 1 & 0.38 \\
\hline 4 ethical use of sfw, technology, and data & 4 & -2 & -0.93 & -2 & -1.11 & 2 & 0.76 & 0 & -0.18 \\
\hline 12 test program reviews & 12 & -2 & -0.93 & -2 & -0.52 & 2 & 0.58 & -1 & -0.68 \\
\hline 2 emerging privacy legislation & 2 & -2 & -0.48 & -1 & -0.42 & -4 & -1.63 & 1 & 0.41 \\
\hline
\end{tabular}


Respondents 2, 11, and 12 form a similar pattern of thinking on the need for investment in "engineering documents," "data sharing," "the ethical use of systems," and "test program reviews" (Table 10). "Emerging privacy legislation" is not an area that is deemed important for investments.

Table 11: Distinguishing Statements for Factor 4

\begin{tabular}{|c|c|c|c|c|c|c|c|c|c|}
\hline \multicolumn{10}{|c|}{ Factors } \\
\hline & & 1 & & 2 & & 3 & & 4 & \\
\hline No. Statement & No. & $\mathrm{RN}$ & SCORE & RNK & SCORE & $\mathrm{RN}$ & SCORE & $\mathrm{RNK}$ & SCORE \\
\hline 18 ROI strategies & 18 & -4 & -1.84 & 0 & -0.09 & 1 & 0.47 & 3 & 1.58 \\
\hline 17 training investments & 17 & -3 & -1.39 & -1 & -0.33 & -2 & -1.10 & 3 & $1.28 *$ \\
\hline 32 citizen engagement & 32 & 3 & 1.33 & -4 & -1.91 & 3 & 1.09 & -1 & $-0.37 *$ \\
\hline 9 prototyping new software solutions & 9 & 2 & 0.88 & 1 & 0.57 & 3 & 1.21 & -3 & $-1.15^{*}$ \\
\hline 5 changes in business related SOP & 5 & -1 & -0.03 & 3 & 1.61 & 0 & 0.16 & -4 & $-1.58 *$ \\
\hline 6 changes in IT related SOP & 6 & -1 & -0.03 & 3 & 1.64 & 0 & 0.16 & -4 & $-1.79 *$ \\
\hline
\end{tabular}

Finally, factor 4 is distinguished by the need for investment in "training" and "return-oninvestment strategies" related to IT systems. These respondents $(5,7,8,9$, and 13) saw little need for investments in assistance with "standard operating procedures" or "prototyping." Table 12 shows the Q-Sample items that did not distinguish any of the factors. It should be noted that this does not imply that none of the respondents deemed these areas as necessary for investment; rather, their thinking on the subjects did not distinguish them from the others.

Table 12: Items That Do Not Distinguish between Any Pair of Factors

\begin{tabular}{|c|c|c|c|c|c|c|c|c|c|}
\hline \multicolumn{10}{|c|}{ Factors } \\
\hline & & 1 & \multicolumn{3}{|c|}{2} & \multicolumn{2}{|l|}{3} & \multicolumn{2}{|l|}{4} \\
\hline No. Statement & No. & RNK & CORE & $\mathrm{RNH}$ & CORE & RNK & SCORE & RNK & CORE \\
\hline 16 technical documentation & 16 & -3 & -1.39 & -1 & -0.35 & -1 & -0.15 & -1 & -0.52 \\
\hline $19 *$ quality assurance & 19 & 2 & 0.88 & 2 & 0.76 & 0 & -0.05 & 1 & 0.50 \\
\hline $20 *$ risk management & 20 & -1 & -0.03 & 1 & 0.01 & -1 & -0.27 & 1 & 0.21 \\
\hline $21^{*}$ estimating cost and schedule & 21 & 1 & 0.43 & 1 & 0.40 & 1 & 0.36 & 2 & 0.87 \\
\hline 22 communications and team building & 22 & 3 & 1.33 & 2 & 0.83 & 1 & 0.56 & 0 & 0.17 \\
\hline
\end{tabular}




\begin{tabular}{|lllllllllll|}
\hline 23 & strategic planning and goal alignment & 23 & 2 & 0.88 & 4 & 1.70 & 2 & 0.89 & 4 & 1.90 \\
\hline 31 & developing feasible and reliable metrics & 31 & -2 & -0.93 & -1 & -0.39 & -3 & -1.32 & -2 & -0.98 \\
\hline
\end{tabular}

In sum, the analysis revealed four patterns of thought: one that stressed security and added value (factor 1), one that stressed process issues (factor 2), one that valued technical support (factor 3), and one that was concerned with training and investment (factor 4). Note that in the analysis, we are less concerned with which respondents fall where and more concerned with the overall pattern of opinions that emerges. Q methodology's strength is in revealing the dominant patterns and clusters of opinions that surface within a group. 


\section{Conclusion}

Q methodology is a method for exploring dominant perceptions or patterns of thought within individuals and among groups. In essence, it is a method that can help to capture and reflect the richness and complexity of various points of view. It is used primarily to identify groups with conflicting values, preferences, and opinions to better understand the differences. It is also often used to identify potential areas for research or action. In the practice of software engineering, Q methodology seems to have potential application in many areas including:

- Measuring the extent and nature of agreement on process improvement objectives

- Measuring the extent and nature of agreement on product functional and quality requirements

- Supplementing reviews of software architectures by measuring the extent to which reviewers believe the architecture satisfies various quality requirements

- Generally illuminating differing perceptions and opinions among project and organizational stakeholders

Q methodology is a tool for uncovering perceptions. It is not a tool for isolating direct cause and effect. In other words, Q methodology is a tool for offering insight but not for prediction. As such, it complements and expands the host of tools project managers currently have at their disposal. It fills a need in that it helps to isolate unknowns. But what ultimately happens to those revealed "unknowns" is beyond the scope of Q methodology. 


\section{Appendix A Glossary}

Concourse

composite statement arrays

Q-Sample

Q-Sort

condition of

instruction

factor

factor loadings

factor scores
A list of items serving as candidates for inclusion in the Q-Sort. It can take the form of questions, statements, pictures, etc.

The composite response set illustrating the average opinions of the respondents that clustered on a factor.

The sample of items that are drawn from the concourse and comprise the instrument that will be provided to the respondents.

Each respondent's rank ordered set of perceptions.

The instructions provided to each respondent.

The cluster of respondents whose Q-Sorts were statistically similar.

Each respondent's correlation with each of the identified clusters or factors.

These scores show the level of consensus/conflict among statements within each opinion cluster. They serve as the basis of interpretation. 


\section{Appendix B Relevant Web Sites}

Q Methodology Network: http://listserv.kent.edu/archives/q-method.html

QA Method for Modern Research: http://www.qmethod.org

Q-Sort: http://www.qmethod.com

QMethod Page: http://www.rz.unibw-muenchen.de/ p41bsmk/qmethod 


\section{References}

URLs are valid as of the publication date of this document.

[Adcock 54] Adcock, C. J. Factorial Analysis for Nonmathematicians.

Melbourne, Australia: Melbourne University Press, 1954.

[Brown 80] Brown, S. R. Political Subjectivity: Applications of Q Methodology in Political Science. New Haven, CT: Yale University Press, 1980.

[Brown 93] Brown, S. R. "A Primer on Q Methodology." Operant Subjectivity 16, 3/4 (April/July 1993): 91-138.

[Dennis 86] Dennis, K. E. "Q Methodology: Relevance and Application to Nursing Research.” Advances in Nursing Science 8, 3 (April 1986): 6-17.

[Dennis 90] Dennis, K. E. "Patients' Control and the Information Imperative: Clarification and Confirmation." Nursing Research 39, 3 (May/June 1990): 162-166.

[McKeown \& Thomas 88]

[Sell \& Brown 84]

McKeown, B. F. \& Thomas, D. B. Q Methodology. Newbury Park, CA: Sage Publications, 1988.

Sell, D. K. \& Brown, S. R. "Q Methodology as a Bridge Between Qualitative and Quantitative Research: Application to the Analysis of Attitude Change in Foreign Study Program Participants," 79-87. In Qualitative Research in Education. Edited by J. L. Vacca \& H. A. Johnson. Kent, OH: Kent State University, Bureau of Educational Research and Service, 1984.

[Stainton 95] Stainton, Rogers R. "Q Methodology," 178-192. In Rethinking Methods in Psychology. Edited by J. A. Smith; R. Harre; \& L. Van Langenhove. Thousand Oaks, CA: Sage Publications, 1995. 
[Steelman \&

Maguire 04]

[Stephenson 53]

[Valenta \& Wigger

97]
Steelman, T. A. \& Maguire L. A. Understanding Participant

Perspectives: Q-Methodology in National Forest Management. http://www.nicholas.duke.edu/faculty/maguire/env316/q5.htm (2004).

Stephenson, W. The Study of Behavior: Q-Technique and Its Methodology. Chicago, IL: University of Chicago Press, 1953.

Valenta, A. L. \& Wigger, U. "Q-Methodology: Definition and Application in Health Care Informatics." Journal of the American Medical Informatics Association 4, 6 (November/December 1997): 501-510. 



\begin{tabular}{|c|c|c|c|c|}
\hline \multicolumn{3}{|c|}{ REPORT DOCUMENTATION PAGE } & \multicolumn{2}{|c|}{$\begin{array}{l}\text { Form Approved } \\
\text { OMB No. 0704-0188 }\end{array}$} \\
\hline \multicolumn{5}{|c|}{ 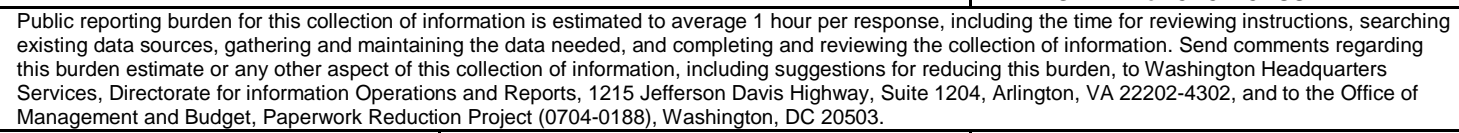 } \\
\hline $\begin{array}{l}\text { AGENCY USE ONLY } \\
\text { (Leave Blank) }\end{array}$ & \multicolumn{2}{|l|}{\begin{tabular}{|ll} 
2. & REPORT DATE \\
& October 2004
\end{tabular}} & \multicolumn{2}{|c|}{$\begin{array}{l}\text { REPORT TYPE AND DATES COVERED } \\
\text { Final }\end{array}$} \\
\hline \multicolumn{3}{|c|}{ 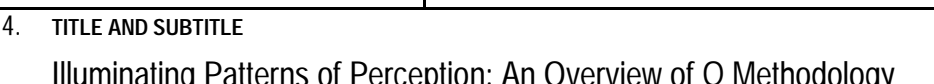 } & \multicolumn{2}{|c|}{$\begin{array}{ll}\text { 5. } & \text { FUNDING NUMBERS } \\
& \text { F19628-00-C-0003 }\end{array}$} \\
\hline \multicolumn{5}{|l|}{$\begin{array}{ll}6 . & \text { AUTHOR(S) } \\
& \text { Maureen }\end{array}$} \\
\hline \multicolumn{3}{|c|}{$\begin{array}{l}\text { 7. PERFOPMNG ORGANZATONNAME(S) AND ADDRESS(ES) } \\
\text { Software Engineering Institute } \\
\text { Carnegie Mellon University } \\
\text { Pittsburgh, PA } 15213\end{array}$} & \multicolumn{2}{|c|}{$\begin{array}{ll}\text { 8. } & \text { PERFORMNG ORGANZATION } \\
\text { REPORT NUMBER } \\
\text { CMU/SEI-2004-TN-026 }\end{array}$} \\
\hline \multicolumn{3}{|c|}{$\begin{array}{ll}9 . & \text { SPONSORING/MONTORING AGENCY NAME(S) AND ADDRESS(ES) } \\
\text { HQ ESC/XPK } \\
\text { 5 Eglin Street } \\
\text { Hanscom AFB, MA 01731-2116 }\end{array}$} & \multicolumn{2}{|c|}{$\begin{array}{l}\text { 10. SPONSORING/MONTORING AGENCY } \\
\text { REPORT NUMBER }\end{array}$} \\
\hline \multicolumn{5}{|l|}{ 11. SUPPLEMENTARY NOTES } \\
\hline \multicolumn{3}{|c|}{ 12A DISTRIBUTION/AVALABIUTYSTATEMENT } & \multicolumn{2}{|c|}{ 12B DISTRIBUTIONCODE } \\
\hline \multicolumn{5}{|c|}{$\begin{array}{l}\text { Q methodology is a research method with a proven history for illuminating agreement and differences among } \\
\text { individual and group perceptions. This technical note describes ways for applying } Q \text { methodology to assist } \\
\text { software engineering processes. As a project management tool, it can help to articulate system requirements } \\
\text { and project risk. It can also be used to identify many of the hidden risks and costs associated with system } \\
\text { efforts. Q methodology complements a project manager's suite of methodologies and tools by providing a } \\
\text { means for uncovering stakeholder perceptions of incorrectly specified requirements, looming risks, and } \\
\text { hidden costs. In doing so, it provides stakeholders and project managers with additional insights for } \\
\text { troubleshooting project threats. }\end{array}$} \\
\hline \multicolumn{3}{|l|}{$\begin{array}{l}\text { 14. SUBJECT TERMS } \\
\text { Q methodology, fa } \\
\text { conflict, software d }\end{array}$} & \multicolumn{2}{|c|}{$\begin{array}{l}\text { 15. NUMBER OF PAGES } \\
31\end{array}$} \\
\hline \multicolumn{5}{|l|}{ 16. PRICECODE } \\
\hline $\begin{array}{l}\text { 17. SECURTY CLASSIFCATION } \\
\text { OF REPORT } \\
\text { Unclassified }\end{array}$ & $\begin{array}{l}\text { 18. SECURIT CLASSIFCATION OF } \\
\text { THIS PAGE } \\
\text { Unclassified }\end{array}$ & $\begin{array}{l}\text { 19. SECURTYCL- } \\
\text { ABSTRACT } \\
\text { Unclassifie }\end{array}$ & SIFCATIONOF & $\begin{array}{l}\text { 20. LMTATION OF ABSTRACT } \\
\text { UL }\end{array}$ \\
\hline
\end{tabular}

